\title{
Effect of Physical Intervention on Preventing Upper Limb Venous Thrombosis of Patients with PICC: A Systematic Review and Meta-Analysis of Randomized Trials
}

\author{
Chunmei Li, Xin Liang, Shulong Cao, Hong Zhou, Haiyuan Zhang* \\ Department of Medicine, Yangtze University, Jingzhou, China \\ Email: `hyzhang_88@163.com
}

How to cite this paper: Li, C.M., Liang, X., Cao, S.L., Zhou, H. and Zhang, H.Y. (2020) Effect of Physical Intervention on Preventing Upper Limb Venous Thrombosis of Patients with PICC: A Systematic Review and Meta-Analysis of Randomized Trials. Yangtze Medicine, 4, 241-253.

https://doi.org/10.4236/ym.2020.44023

Received: November 28, 2019

Accepted: September 27, 2020

Published: September 30, 2020

Copyright $\odot 2020$ by author(s) and Scientific Research Publishing Inc. This work is licensed under the Creative Commons Attribution International License (CC BY 4.0).

http://creativecommons.org/licenses/by/4.0/

cc) (i) Open Access

\begin{abstract}
Objective: To evaluate the effect of physical methods on the prevention of venous thrombosis in patients with peripherally inserted central catheter (PICC). Methods: Randomized controlled trials meeting the inclusion and exclusion criteria were retrieved from the following databases: Cochrane library, Pubmed, EMbase, Web of science, Ovid, CBM, CNKI, Wanfang, VIP, then Review Manage (RevMan) 5.3 software was used for data analysis. Results: A total of 24 RCTs including 3496 patients were analyzed in the study. The results of meta-analysis showed that various forms of upper limb movements could effectively decrease the incidence of venous thrombosis in the patients with PICC $[R R=0.23,95 \% C I(0.16,0.33), P<0.01]$, upper limb movements could effectively improve the mean blood flow velocity of basilic vein $[M D=1.65,95 \% C I(1.19,2.11), P<0.01]$. Conclusion: Upper limb movements can effectively decrease the incidence of phlebothrombosis and improve the mean flow velocity of basilic vein in the patients undergoing PICC. Other forms of physical prevention methods need to be further studied due to insufficient sample size.
\end{abstract}

\section{Keywords}

PICC, Upper Limb Movements, Venous Thrombosis, Blood Flow Velocity, Meta-Analysis

\section{Introduction}

Peripherally inserted central catheter (PICC) is a kind of central venous catheter punctured by peripheral veins, such as the basilic vein, cubital median vein, ce- 
phalic vein [1]. While providing convenient and effective venous access for patients, PICC can also cause some complications, such as shedding, blockage, phlebitis, venous thrombosis, etc., among which venous thrombosis is the most serious, if the thrombus falls off, it will lead to fatal pulmonary embolism [2] [3]. How to prevent venous thrombosis is an urgent problem to be solved in clinical practice. The damage of blood vessel wall, slow blood flow and high blood coagulation state are the three main factors causing venous thrombosis. The endovascular intima was directly damaged during catheterization of PICC. At the same time, as a foreign body floating in the blood vessel for a long time, it can generate mechanical stimulation and affect normal hemodynamics, easily forming eddy-current and producing microthrombus. In addition, after the placement of PICC, patients will also suffer from pain, weakness, bed rest, worry and other factors, as well as physical reactions such as nausea and vomiting after chemotherapy, resulting in decreased voluntary activities, blood stasis, slow blood flow and easy formation of thrombosis. Other predisposing factors include the stimulation of blood vessels by drugs. Tumor cells damage the hypercoagulability of vascular endothelial cells by directly invading blood vessels or secreting vascular penetrating factors, and directly activate the coagulation system and the activation of a variety of coagulant substances to promote thrombosis. The prevention of thrombosis is mainly to use physical or drug methods to prevent the formation of three factors. Current guidelines [4] do not recommend drug treatment for venous thrombosis patients with PICC, therefore, it is urgent for us to find safe, simple and effective physical intervention measures to prevent venous thrombosis. Physical interventions refer to the methods that use physical principles such as motion, light, electricity, radiation, pressure and machinery to achieve the purpose of prevention. At present there are few studies about physical intervention measures for venous thrombosis in foreign countries, although there are more and more studies about the topic in China, the research standards and methods are different. The aim of this study was to evaluate the effect of various physical intervention methods for PICC venous thrombosis, in order to provide evidence and direction for future studies.

\section{Materials and Methods}

\subsection{Inclusion Criteria}

1) Study design: randomized controlled trials (RCTs) about physical prevention of upper limb venous thrombosis in patients with PICC. 2) There was no significant difference in the general data between the two groups in age or gender $(P>$ 0.05). 3) Patients: aged at least 18 years old; completed PICC for the first time; tolerate color ultrasound examination. 4) Interventions: the experimental group received physical prevention during PICC indentation, the control group didn't receive intervention during PICC indwelling or received another form of physical prophylaxis. Specific physical mode: every day, the medical staff conducted guidance and supervision on the movement mode of the affected limb in differ- 
ent modes and frequencies. Regular exercise: the nurse only carries on the health education of the physical exercise mode to the patient, but does not supervise the implementation. 5) Outcome indicators: the main outcome indicators in this study were the incidence of venous thrombosis and the mean velocity of blood flow. Venous thrombosis and venous velocity were determined by color Doppler examination. Normal vein ultrasound showed thin, smooth vein wall, no echo in the lumen, the probe pressure lumen can be compressed, the color blood flow filling good. In the case of venous thrombosis, the inner diameter of the lumen increases, the wall thickens, there are low or moderate echoes around the catheter, and color Doppler flow signals are filled with defective or no color flow signals at all. Venous velocity was compared with that of the patient at steady state.

\subsection{Exclusion Criteria}

1) Multiple deep vein catheterization ( $>2$ times); 2$)$ use drug treatment for intervention.

\subsection{Search Strategy}

1) Searchable database: This study systematically searched relevant published original literatures in Chinese and English databases, including Pubmed, Web of sciene, EMbase, Ovid, Cochrane library, CBM, CNKI, Wanfang, VIP. The retrieval time is from their inception until August 2019. 2) Search terms: "arm exercise/make a fist/arm training/upper limb movement/limb function exercise", "PICC/peripherally inserted central catheter", "phlebothrombosis/venous thrombosis/thrombus of vein/venous embolism/deep vein thrombosis", "prevention and control".

\subsection{Study Selection and Quality Evaluation}

1) Study screening and data extraction: According to the consistent inclusion and exclusion criteria, the data was selected and extracted by two researchers independently, the two researchers have learned knowledge about evidence-based medicine, and received standardized training. Extract contents including basic information (author, year of publication, country, baseline situation, etc.), research design, sample size, interventions, outcome indicators, etc. Any disagreement was resolved by discussion with a third reviewer. 2) The two researchers independently evaluated the included studies according to Cochrane Assessment Manual 5.1.0 Assessment Criteria. The evaluation items included: random sequence generation, allocation hiding, blind method, data integrity of outcome indicators, selective reporting of findings and other sources of bias. A: fully meet the above criteria, the risk of a variety of bias is low; B: partially meet the above criteria, bias risk is moderate; C: completely dissatisfied with the above criteria, bias risk is higher. Both A and B studies were included in this study.

\subsection{Statistical Analysis}

Meta-analysis was performed using the RevMan5.3 software, provided by Coch- 
rane collaboration network. Weighted mean difference $(M D)$ was used for measurement data, such as the venous blood flow velocity. Relative Risk $(R R)$ was used for enumeration data. 95\% Confidence interval $(C I)$ was calculated for all analyses. Firstly, Chi-square $\left(X^{2}\right)$ was used to confirm whether there was heterogeneity among the studies. If there was no significant statistical heterogeneity $\left(P>0.1, I^{2}<50 \%\right)$, the fixed effect model was adopted. If there was heterogeneity $\left(P<0.1, I^{2} \geq 50 \%\right)$, the random effect model was used to combine with the effect size. Descriptive analysis was adopted if heterogeneity was too obvious and can't be judged.

\section{Results}

\subsection{Study Selection and Study Characteristics}

A total of 579 trials were initially retrieved, 334 are Chinese and 245 are English. After screening, 24 literatures were finally included, and the specific steps of inclusion were shown in Figure 1. Three literatures [5] [6] [7] divided the intervention group into two groups (experimental group 1 and experimental group 2). The two groups had different exercise frequency, in order to make the data clearer and the consistency of intervention measures and outcome indicators, the two groups were divided into two RCTs. The basic features of the included articles are shown in Table 1.

\subsection{Methodological Quality Evaluation of the Included Literature}

The methodological quality of the included 24 trials was all of grade B. The baseline levels of the subjects were compared. Two of the studies [7] [8] made an intentionality analysis of the missing patients, and the specific evaluation indicators and results were shown in Table 2.

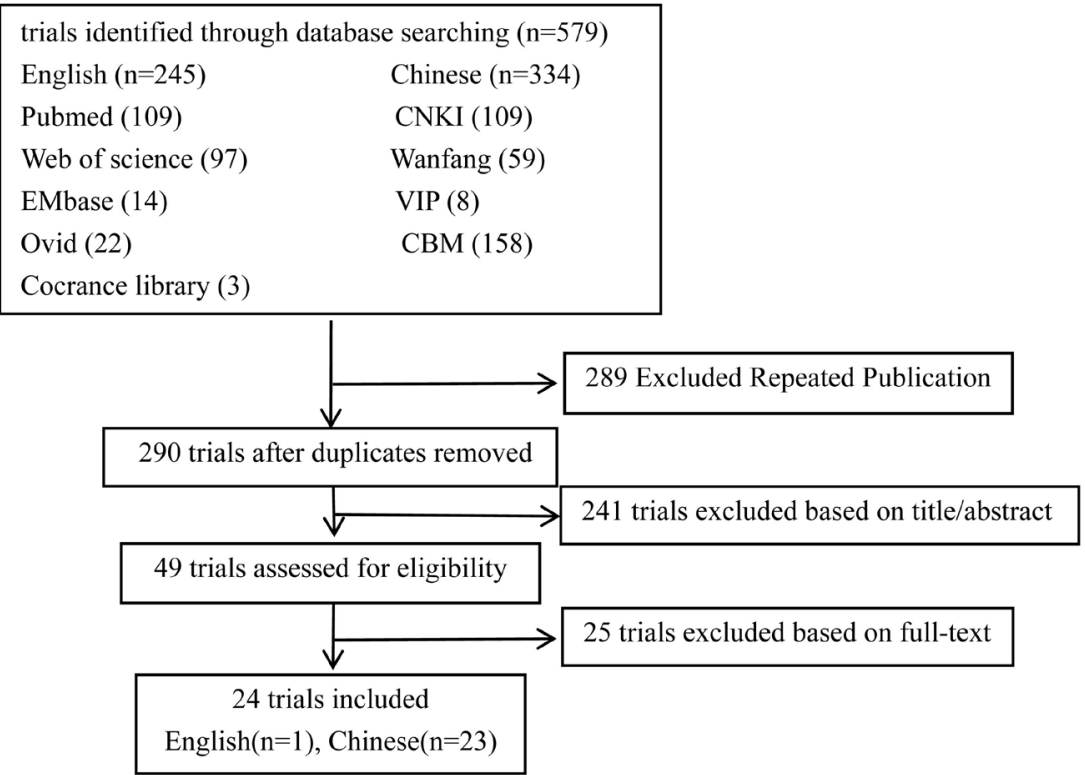

Figure 1. Flow diagram of studies identified in the systematic review. 
Table 1. Characteristics of the included studies.

\begin{tabular}{|c|c|c|c|c|c|c|c|}
\hline \multirow{2}{*}{ Included studies } & \multirow{2}{*}{ Year } & \multirow{2}{*}{ Nation } & \multirow{2}{*}{ Objective } & \multirow{2}{*}{$\begin{array}{c}\text { Sample } \\
\text { size E/C }\end{array}$} & \multicolumn{2}{|c|}{ Interventions } & \multirow{2}{*}{$\begin{array}{l}\text { Outcome } \\
\text { indicator }\end{array}$} \\
\hline & & & & & E & $\mathrm{C}$ & \\
\hline Chen, B. [5] & 2016 & China & Tumour & $40 / 40$ & Electronic grip & $\mathrm{R}$ & $\mathrm{B}+\mathrm{D}$ \\
\hline Zhang, M. [6] & 2015 & China & Hepatobiliary Surgery & $20 / 20$ & Electronic grip & $\mathrm{R}$ & $\mathrm{B}+\mathrm{D}$ \\
\hline Zhou, Y. [7] & 2015 & China & Tumour & $32 / 38$ & $\begin{array}{c}\text { Elastic ball } \\
\text { handgrip exercise }\end{array}$ & $\mathrm{R}$ & $\mathrm{DVT}+\mathrm{A}$ \\
\hline Rabinstein [8] & 2019 & USA & $\begin{array}{c}\text { Neurocritical } \\
\text { patients }\end{array}$ & $31 / 31$ & $\begin{array}{c}\text { Sequential } \\
\text { compression devices }\end{array}$ & $\begin{array}{c}\text { without pressure } \\
\text { treatment }\end{array}$ & DVT \\
\hline Hao, R. N. [9] & 2016 & China & $\begin{array}{l}\text { Gastrointestinal } \\
\text { tumor }\end{array}$ & $83 / 83$ & Arm exercise & $\mathrm{R}$ & DVT \\
\hline Li, L. [10] & 2018 & China & $\begin{array}{l}\text { Hematological } \\
\text { tumor }\end{array}$ & $159 / 159$ & Active fist-making & $\mathrm{R}$ & $\mathrm{DVT}+\mathrm{A}$ \\
\hline Li, Q. [11] & 2017 & China & $\begin{array}{c}\text { Tumor } \\
\text { chemotherapy }\end{array}$ & $113 / 110$ & $\begin{array}{l}\text { Video combined with } \\
\text { drawing exercise }\end{array}$ & $\mathrm{R}$ & DVT \\
\hline Lun, X. P. [12] & 2014 & China & Tumor & $43 / 43$ & Upper limb exercise & $\mathrm{R}$ & DVT \\
\hline Ren, Y. C. [13] & 2018 & China & Tumour & $52 / 52$ & Handgrip exercise & $\mathrm{R}$ & $\mathrm{DVT}+\mathrm{A}$ \\
\hline Wang, M. [14] & 2016 & China & $\begin{array}{c}\text { Cerebrovascular } \\
\text { disease }\end{array}$ & $42 / 42$ & Active fist clenching & $\mathrm{R}$ & $\mathrm{DVT}+\mathrm{A}$ \\
\hline Wang, Y. P. [15] & 2018 & China & Tumour & $42 / 42$ & Ball grip exercise & $\mathrm{R}$ & DVT \\
\hline Wang, Z. Y. [16] & 2017 & China & $\begin{array}{l}\text { Hematological } \\
\text { tumor }\end{array}$ & $87 / 88$ & $\begin{array}{c}\text { Quantitative physical } \\
\text { intervention }\end{array}$ & $\mathrm{R}$ & DVT \\
\hline Wu, T. T. [17] & 2017 & China & Leukemia & $76 / 84$ & Functional exercise & $\mathrm{R}$ & DVT \\
\hline Xie, F. M. [18] & 2019 & China & $\begin{array}{l}\text { Hematological } \\
\text { tumor }\end{array}$ & $87 / 88$ & $\begin{array}{l}\text { Music grip } \\
\text { strength training }\end{array}$ & $\mathrm{R}$ & DVT \\
\hline Yin, R. H. [19] & 2017 & China & Tumour & $60 / 60$ & $\begin{array}{l}\text { Quantitative PICC } \\
\text { functional exercise }\end{array}$ & $\mathrm{R}$ & DVT \\
\hline Zhang, J. W. [20] & 2019 & China & Elderly patients & $75 / 75$ & Fisting activity & $\mathrm{R}$ & $\mathrm{DVT}+\mathrm{A}$ \\
\hline Zhu, W. Y. [21] & 2019 & China & Tumor & $42 / 42$ & $\begin{array}{l}\text { Different ball holding } \\
\text { motion patterns }\end{array}$ & $\mathrm{R}$ & $\mathrm{DVT}+\mathrm{A}$ \\
\hline Zou, X. M. [22] & 2014 & China & Breast cancer & $80 / 80$ & Grip training & $\mathrm{R}$ & DVT \\
\hline Xia, R. [23] & 2010 & China & SENILE tumor & $60 / 60$ & $\begin{array}{c}\text { Electric } \\
\text { acupoint stimulation }\end{array}$ & $\mathrm{R}$ & $\mathrm{DVT}+\mathrm{A}$ \\
\hline Zhang, J. [24] & 2019 & China & tumor & $137 / 137$ & $\begin{array}{l}\text { Microwave hyperthermia } \\
\text { combining with } \\
\text { limb movement }\end{array}$ & $\mathrm{R}$ & DVT \\
\hline Lin, L. Z. [25] & 2018 & China & tumor & $150 / 150$ & Microwave physiotherapy & $\mathrm{R}$ & $\mathrm{D}$ \\
\hline Wang, J. M. [26] & 2013 & China & cancer & $45 / 45$ & Static and static pulse system & $\mathrm{R}$ & DVT \\
\hline Zhu, B. Z. [27] & 2019 & China & tumor & $86 / 85$ & $\begin{array}{l}\text { Compression with } \\
\text { sphygmomanometer }\end{array}$ & $\mathrm{R}$ & DVT \\
\hline Jin, L. [28] & 2015 & China & tumor & $100 / 100$ & $\begin{array}{l}\text { Air wave pressure } \\
\text { therapeutic apparatus }\end{array}$ & $\mathrm{R}$ & DVT \\
\hline
\end{tabular}

Note: A: blood flow velocity in axillary vein; B: the mean flow velocity of basilic vein; D: Blood vessel diameter; DVT: Incidence of deep vein thrombosis; R: regular exercise; C: control group; E: experimental group. 
Table 2. Assessment of risk of bias.

\begin{tabular}{|c|c|c|c|c|c|c|c|}
\hline $\begin{array}{l}\text { Included } \\
\text { studies }\end{array}$ & $\begin{array}{l}\text { Random sequence } \\
\text { generation }\end{array}$ & $\begin{array}{l}\text { Allocation } \\
\text { concealment }\end{array}$ & $\begin{array}{l}\text { Blinding of } \\
\text { participants }\end{array}$ & $\begin{array}{c}\text { Blinding of } \\
\text { outcome assessment }\end{array}$ & $\begin{array}{l}\text { Incomplete } \\
\text { outcome data }\end{array}$ & $\begin{array}{l}\text { Other } \\
\text { bias }\end{array}$ & $\begin{array}{l}\text { Quality } \\
\text { grade }\end{array}$ \\
\hline Chen, B. [5] & low & unclear & unclear & low & low & low & B \\
\hline Zhang, M. [6] & unclear & unclear & unclear & low & low & low & B \\
\hline Zhou, Y. [7] & low & unclear & unclear & unclear & low & low & B \\
\hline Rabinstein [8] & low & low & high & low & high & low & B \\
\hline Hao, R. N. [9] & low & unclear & & unclear & low & low & B \\
\hline Li, L. [10] & low & unclear & unclear & unclear & low & low & B \\
\hline $\mathrm{Li}, \mathrm{Q} .[11]$ & unclear & unclear & unclear & unclear & low & low & B \\
\hline Lun, X. P. [12] & low & unclear & unclear & unclear & low & low & B \\
\hline Ren, Y. C. [13] & low & unclear & unclear & unclear & low & low & B \\
\hline Wang, M. [14] & unclear & unclear & unclear & unclear & low & low & B \\
\hline Wang, Y. P. [15] & unclear & unclear & high & unclear & low & low & B \\
\hline Wang, Z. Y. [16] & low & unclear & unclear & unclear & low & low & B \\
\hline Wu, T. T. [17] & unclear & unclear & unclear & unclear & low & low & B \\
\hline Xie, F. M. [18] & low & unclear & unclear & unclear & low & low & B \\
\hline Yin, R. H. [19] & unclear & unclear & unclear & unclear & low & low & B \\
\hline Zhang, J. W. [20] & low & unclear & unclear & unclear & low & low & B \\
\hline Zhu, W. Y. [21] & low & unclear & unclear & unclear & low & low & B \\
\hline Zou, X. M. [22] & low & unclear & unclear & unclear & low & low & B \\
\hline Xia, R. [23] & unclear & unclear & unclear & unclear & low & low & B \\
\hline Zhang, J. [24] & low & unclear & unclear & unclear & low & low & B \\
\hline Lin, L. Z. [25] & low & unclear & unclear & unclear & low & low & B \\
\hline Wang, J. M. [26] & unclear & unclear & high & unclear & low & low & B \\
\hline Zhu, B. Z. [27] & low & unclear & high & unclear & low & low & B \\
\hline Jin, L. [28] & low & unclear & unclear & unclear & low & low & B \\
\hline
\end{tabular}

\subsection{Results of Meta-Analysis}

\subsubsection{Effect of Upper Limb Exercise on Venous Thrombosis}

15 literatures [5] [9]-[22] evaluated the effect of clenched fist exercise on venous thrombosis, and the combined results showed that there was no heterogeneity between the studies $\left(I^{2}=0 \%, P=1.00\right)$, the fixed effect model was used. The results showed that the incidence of phlebothrombosis in the upper limb exercise group was lower than that of the conventional exercise group, and the difference was statistically significant $[R R=0.23,95 \% C I(0.16,0.33), P<0.01]$, as shown in Figure 2.

\subsubsection{Effect of Exercise on the Venous Blood Flow Velocity of Basilic Vein}

2 studies [5] [6] reported the effect of exercise on the venous blood flow velocity 


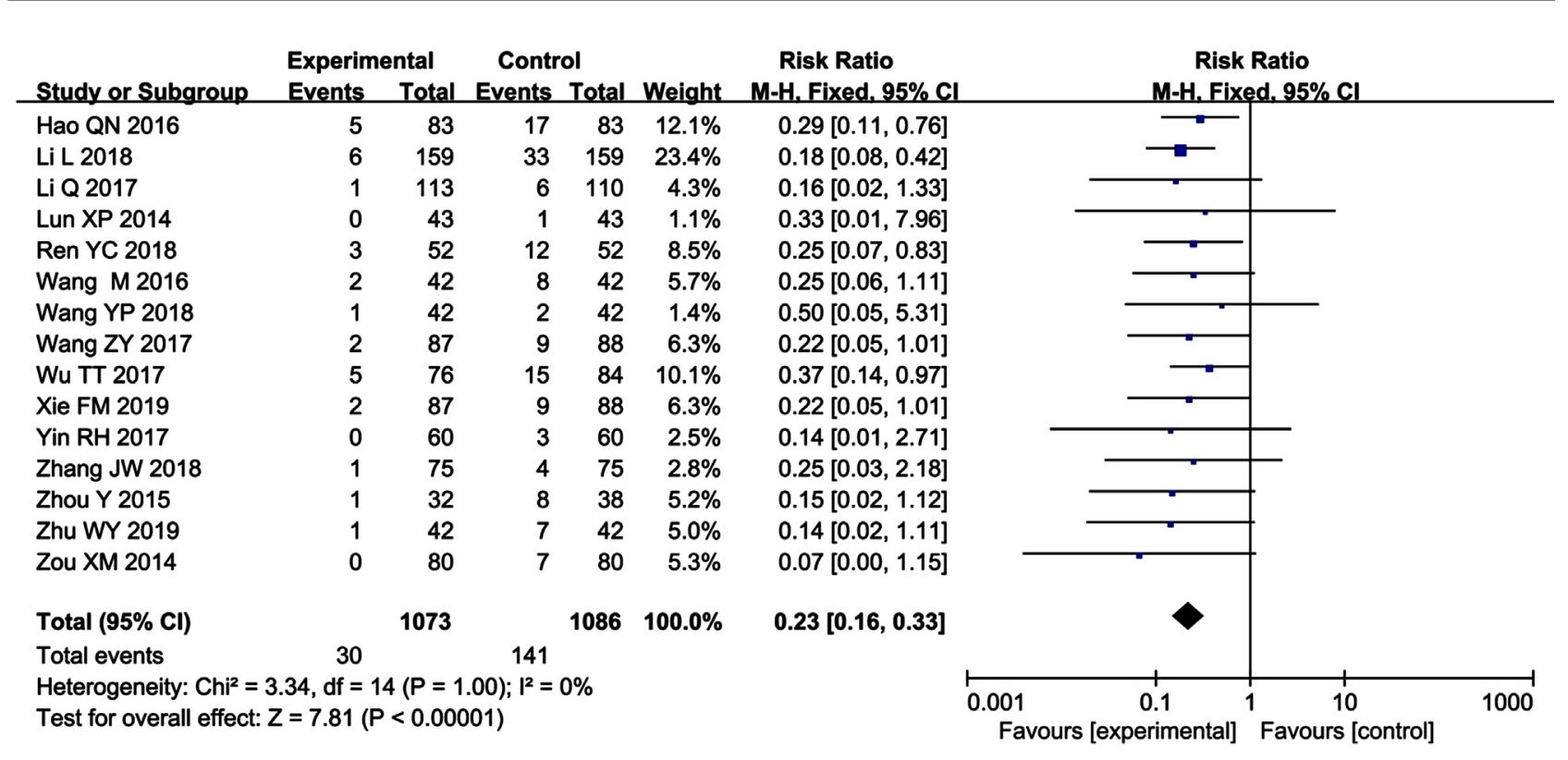

Figure 2. Effect of clenched fist exercise on thrombus.

of basilic vein of patients with PICC. The combined results showed that there was no heterogeneity between the studies $\left(I^{2}=0 \%, P=0.70\right)$, there is no heterogeneity. By using the fixed effects model, the results showed that the venous blood flow velocity of basilic vein in the exercise group movement is faster than that of the routine group, the difference was statistically significant $[R R=1.65$, 95\% $C I(1.19,2.11), P<0.01]$, as shown in Figure 3.

\subsubsection{Effect of Exercise on Blood Flow Velocity in Axillary Vein}

6 studies [5] [10] [13] [14] [20] [21] evaluated the effect of exercise on the blood flow velocity of axillary vein in patients with PICC. 3 studies [5] [20] [21] were excluded for inconsistent thrombotic measurement time, but heterogeneity still existed $\left(I^{2}=92 \%, P<0.001\right)$, as shown in Figure 4. Descriptive analysis showed that all the 6 studies indicated that the velocity of axillary vein after exercise was faster than that of conventional exercise, and the difference was statistically significant $(P<0.05)$.

\subsubsection{Effect of Bioelectrical Stimulation on Thrombosis}

1 literature [23] evaluated the effect of electrical stimulation on vein of patients with PICC catheterization. It was concluded that the difference of axillary vein blood flow velocity and the incidence of deep venous thrombosis between the experimental group and the control group was statistically significant.

\subsubsection{Effect of Microwave on Vein Thrombosis in Patients with PICC Catheterization}

2 literatures [24] [25] evaluated the effect of microwave on vein thrombosis in patients with PICC catheterization. One literature [24] showed that the incidence of venous thrombosis in microwave group was lower than that in control group, and the difference was statistically significant $(P<0.05)$. One literature 


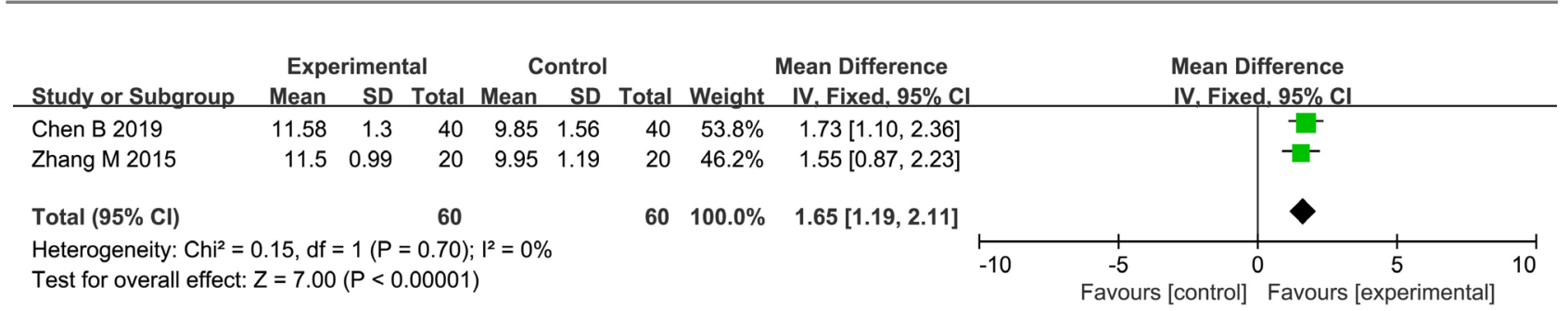

Figure 3. Effect of exercise on the venous blood flow velocity of basilic vein.

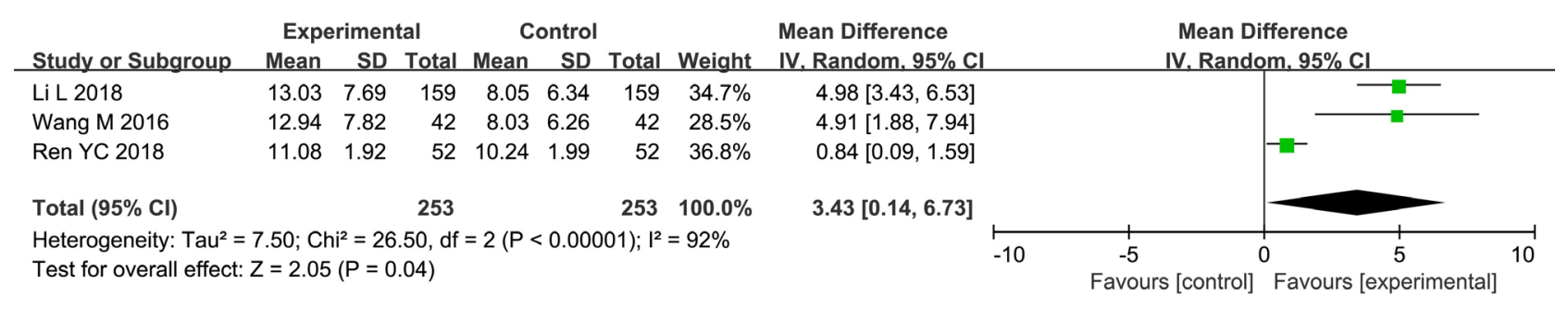

Figure 4. Effect of exercise on blood flow velocity in axillary vein.

[25] evaluated the effect of microwave on the diameter of basilic vein in patients with PICC catheterization. The result showed that the inner diameter of cardinal vein in microwave group was significantly dilated with higher success rate at a time than that of control group and the difference was statistically significant ( $P$ $<0.05)$. Due to the different outcome indexes of the two literatures, meta-integration could not be carried out, and only descriptive analysis was conducted.

\subsubsection{Effect of Pressure on Venous Thrombosis in Patients with PICC}

3 domestic studies [26] [27] [28] evaluated the effect of pressure on venous thrombosis in patients with PICC. Heterogeneity showed that fixed effect model should be selected to analyze $\left(I^{2}=0 \%, P=0.96\right)$. The results showed that the incidence of thrombosis in the pressure group was lower than that of the conventional exercise group, and the difference was statistically significant $[R R=0.22$, 95\% $C I(0.09,0.55), P<0.01]$, as shown in Figure 5.

\subsubsection{Sensitivity Analysis and Publication Bias}

Funnel plot analysis was performed on 15 literatures [5] [9]-[22]. Through sensitivity analysis about the above combined results, the meta-analysis results had no change, suggested that the results of this study are stable. Scatter plots show a symmetrical distribution. The test results of 15 studies are symmetrical without publication bias, as shown in Figure 6.

\subsubsection{Effect of Catheter Material on Venous Thrombosis in PICC Patients} In this paper, 14 [5] [6] [7] [9] [11] [13] [15] [17] [20] [23] [24] [25] [26] [27] studies mentioned that the PICC catheters used are all Brands, and 9 [10] [12] [14] [15] [16] [19] [21] [22] [28] studies did not describe the brands, this is consistent with Li Xin [29]. Related studies [30] [31] pointed out that the incidence of complications of domestic PICC in patients with PICC catheterization was 


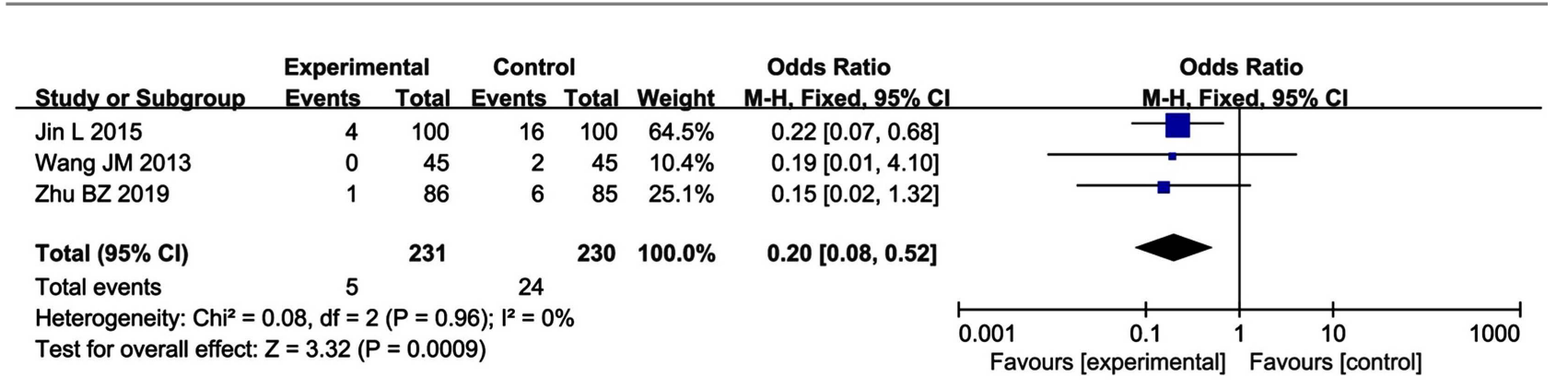

Figure 5. Effect of pressure on thrombus in patients with PICC.

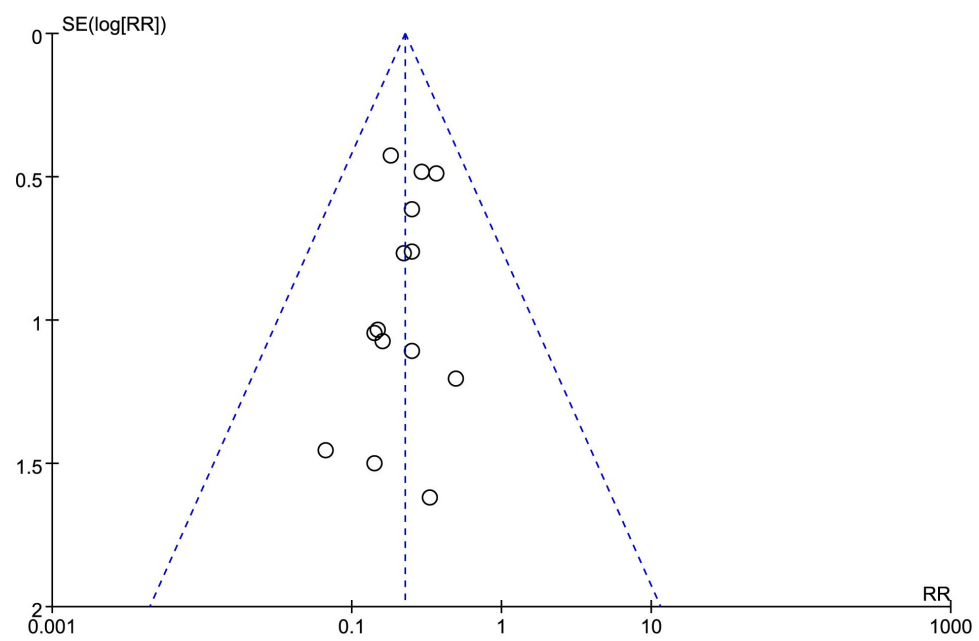

Figure 6. Publication bias of effect of clenched fist exercise on thrombus.

$20 \%(6 / 30)$ and $10.3 \%(7 / 68)$, which was the same as foreign brands ( $8 \%-50 \%)$ [32]. Meanwhile, Seckold, T. pointed out that there was no difference in the total incidence of complications of catheters in terms of materials, but the types of complications were different. The incidence of complications of PICC catheters of different brands is shown in Table 3.

\section{Discussion}

\subsection{Effect of Physical Exercise on the Incidence of Thrombosis in Patients with PICC}

There are many ways to prevent thrombus in patients with PICC. The results of meta-analysis show that all kinds of upper limb movements can reduce the incidence of thrombus in patients with PICC and accelerate the blood flow speed of venous catheterization. Although there are different forms of upper limb movements, they can through the movement of upper limbs to accelerate the blood flow speed of the limb on the side of catheterization, promote the venous and lymphatic circulation, so as to reduce the incidence of thrombus. Some studies have confirmed that [33] [34], compliance of exercise is positively related to the incidence of thrombus in patients with PICC, patients with good compliance have better exercise effect than patients with regular exercise, and the incidence of thrombus is low. It may be due to the lack of supervision of the patients in the 
Table 3. The incidence of complications of PICC of different brands.

\begin{tabular}{ccccc}
\hline Brand & $\begin{array}{c}\text { Complication } \\
\text { incidence }\end{array}$ & $\begin{array}{c}\text { Normal } \\
\text { cases }\end{array}$ & $\begin{array}{c}\text { Total } \\
\text { cases }\end{array}$ & $\begin{array}{c}\text { Total } \\
\text { complication rate }\end{array}$ \\
\hline Kangxin [30] & 7 & 61 & 68 & $10.3 \%$ \\
Domestic brands [31] & 6 & 24 & 30 & $20 \%$ \\
Foreign brands [32] & - & - & 3767 & $8 \%-50 \%$ \\
\hline
\end{tabular}

Note: “-” means no relevant data.

routine exercise group, few of them aware the importance of exercise, fear of the adverse consequences of the activity on the body, resulting in the failure of the exercise intensity and frequency to reach the standard, therefore, the blood flow of the limb on the catheter side is slow, which is easy to cause thrombosis. This study failed to confirm that bioelectric stimulation and microwave can reduce the incidence of venous thrombosis in patients with PICC, which may be related to the fact that this study is less involved in related studies, the implementation process of bioelectricity is relatively cumbersome, and the cost is high, the number of patients received in clinical is less or the intervention time is short, etc., and it is expected that large sample and high-quality randomized controlled trials to be further explored.

The relationship between pressure and venous thrombosis is uncertain. Domestic studies [26] [27] [28] have confirmed that intermittent pressure can reduce the incidence of venous thrombosis. This study found that the upper limb movements can effectively improve the average blood flow velocity of the vein and slow down the formation of thrombus. Therefore, effective education should be provided to patients with PICC, reasonable limb movements and physical therapy should be guided to reduce their fear of exercises and physical pain, and improve patients' compliance and initiative of exercise. However, the incidence of PICC catheterization in foreign countries is low, only one study included, so the sample size is small, and in the course of the study, the treatment group was forced to suspend the experiment due to the high incidence of thrombus, and the integrity of the outcome data was affected. Therefore, more high-quality RCTs and multilingual literatures are needed to evaluate the effect of intermittent pressure on thrombosis.

PICC with different brands, types and materials have been used in China. According to the survey [29], more than $94.6 \%$ of PICC catheters in the market are imported brands such as BARD, USA, BD, ARROW, MEDCOMP, B BRAUN, while the utilization rates of domestic brands are low, such as BAIDUOAN and EILANG, which may be related to the late start of PICC in China. With the improvement of catheterization and maintenance technology of domestic PICC, and the gradual improvement of the brand, its complications are also decreasing, and the price is half of that of imported brands [30], so it may be more suitable for patients in China. However, there are fewer literature about the related complications of domestic brands, more high-quality RCTs studies are needed for 
the comparing between domestic and foreign brands, to promote the development of intravenous therapy specialty in China.

\subsection{Limitations of This Study}

Most RCTs included are Chinese, only one [8] is English, and this study only retrieves the published Chinese and English trials, some trials may not be included. There are great differences in the sample and methodology of the included studies, and the intervention schemes are not consistent, which may have a certain impact on the results of the study. Some studies did not illustrate the generation of random sequence and blinding of allocation, which may also affect the results of Meta analysis. In addition, the quality of the studies included in this study is low, there is a certain risk of bias, and the effect of exercise needs to be further studied and practiced. It is suggested that future research should standardize the interventions. For example, the exercise of mode, method, frequency, intensity, measurement time and standard of outcome indicators, etc., should be refined and specific economic conditions and willingness of the patients should to be taken into consideration, so as to improve the consistency of the prevention. In the future, we can expand the sample size and carry out high-quality randomized controlled trials to validate the effect of standardized physical prevention on venous thrombosis of patients with PICC, and provide more comprehensive theoretical support for clinical nursing staff.

\section{Conflicts of Interest}

The authors declare no conflicts of interest regarding the publication of this paper.

\section{References}

[1] Gorski, L.A. (2017) The 2016 Infusion Therapy Standards of Practice. Home Healthcare Now, 35, 10-18. https://doi.org/10.1097/NHH.0000000000000481

[2] Feng, Z.C. and Zhang, H. (2011) Progress in Prevention and Treatment of PICC-Related Venous Thrombosis in Cancer Patients. Chinese Journal of Misdiagnosis, 11, 6325-6326.

[3] Cooray, R. and Lake, C. (2015) Prevention of Deep Vein Thrombosis and Pulmonary Embolism. Anaesthesia \& Intensive Care Medicine, 16, S1472029915001563. https://doi.org/10.1016/j.mpaic.2015.06.017

[4] Lyman, G.H., Bohlke, K., Khorana, A.A., et al. (2015) Venous Thromboembolism Prophylaxis and Treatment in Patients with Cancer: American Society of Clinical Oncology Clinical Practice Guideline Update 2014. Journal of Clinical Oncology, 33, 654-656. https://doi.org/10.1200/JCO.2014.59.7351

[5] Chen, B. (2016) Effect of Different Fist Clenching Methods on Flow Rate and Diameter of the Basilic Vein before and after PICC Placement. Journal of Nursing, 31, 47-49.

[6] Zhang, M., Fang, X.X., Li, M.E., et al. (2015) Effect of Handgrip Exercise on Blood Flow Velocity and Blood Vessel Diameter Changes of Basilic Vein in Patients Wim Peripherally Inserted Central Catheter. China's Practical Nursing, 31, 94-98. 
[7] Zhou, Y., Liu, K.Y. and Cui, Y. (2015) Best Handgrip Exercise in Prevention of Upper Extremity Deep Vein Thrombosis after PICC. Jiangsu Medical Journal, 41, 1303-1305.

[8] Rabinstein, A.A., Hellickson, J.D., Macedo, T.A., et al. (2019) Sequential Pneumatic Compression in the Arm in Neurocritical Patients with a Peripherally Inserted Central Venous Catheter: A Randomized Trial. Neurocritical Care, 901, 1-6. https://doi.org/10.1007/s12028-019-00765-w

[9] Hao, R.N., Hu, F. and Tang, W.B. (2016) Observation on the Effect of Arm Exercise on Prevention of Venous Thrombosis after Placing PICC in Patients with Gastrointestinal Tumor. Journal of Nursing, 23, 19-21.

[10] Li, L., Mei, C.L., Liu, X.Y., et al. (2018) Effect of Active Fist-Making on Prevention of Upper Limb Vein Thrombosis Associated with Peripheral Venous Puncture Central Venous Catheterization (PICC). Medical Equipment, 31, 1-2.

[11] Li, Q. and Xu, L.Z. (2017) Effect of Video Combined with Drawing Exercise on Prevention of Upper Limb Edema and Thrombosis in Patients with PICC Catheterization. General Nursing, 15, 2000-2001.

[12] Lun, X.P., Chen, M.Y., Zhou, H.Y., et al. (2014) Application of Upper Limb Exercise in Prevention of Venous Thrombosis in Patients with PICC Catheterization. Journal of Clinical Medicine, 1, $966+969$.

[13] Ren, Y.C. (2018) Prevention Effects of Handgript Exercise on Upper Extremity Venous Thrombosis in Patients with PICC Catheterization. Chinese Journal of Thrombosis and Hemostasis, 24, 1027-1029 + 1032.

[14] Wang, M. (2016) Effect of Active Fist Clenching on Prevention of PICC-Related Upper Limb Venous Thrombosis. Nursing Practice and Research, 13, 141-142.

[15] Wang, Y.P., Tang, L., Bao, Z.L., et al. (2018) Clinical Effect of Ball Grip Exercise on Patients with PICC Catheterization and Dietary Nursing Observation. Modern Digestion and Interventional Diagnosis and Treatment, 23, 200-201.

[16] Wang, Z.Y. (2017) Quantitative Physical Intervention to Prevent Blood Clots Blood Cancer Center Venipuncture Correlation Analysis Results. Journal of Snake, 29, 499-500.

[17] Wu, T.T. and Mei, J.H. (2017) Effect of Functional Exercise on Prevention of Thrombosis after PICC Implantation in Leukemia Patients. Chinese Journal of Maternal and Child Health, 28, 62-63.

[18] Xie, F.M., Huang, H.Q., Zhou, X.M., et al. (2019) Effect of Music Grip Strength Training on Prevention of PICC Catheters in Patients with Blood Tumor. Guangxi Medical Journal, 41, 1326-1328.

[19] Yin, R.H., Wang, S.M. and Cai, Y.H. (2017) Application of Quantitative PICC Functional Exercise in PICC Patients. Nursing Research, 31, 3712-3714.

[20] Zhang, J.W. and Fu, R. (2018) Effects of Fisting Activity in Preventing Deep Venous Thrombosis in Elderly Patients with PICC. Chinese Journal of Modern Nursing, 24, 440-442.

[21] Zhu, W.Y. and Xu, Z.L. (2019) Analysis of the Effect of Different Ball Holding Motion Patterns on Venous Blood Flow and Related Thrombosis in Patients with PICC Catheterization. Journal of Clinical Medicine, 6, 80-81.

[22] Zou, X.M. (2014) Application Effects of Grip Training in Breast Cancer Patients with PICC Treatment. PLA Nursing Journal, 31, 68-70 + 76.

[23] Xia, R., Li, Z.Y., Su, L., et al. (2010) Effects of Electric Acupoint Stimulation on Prevention of Elderly Tumor Patients with Deep Venous Thrombosis after PICC Op- 
eration. Chinese Journal of Modern Nursing, 16, 269-271.

[24] Zhang, J., Li, A.M., Chang, Z.W., et al. (2019) Microwave Hyperthermia Combining with Iimb Movement Prevents Venous Thrombosis in wncer Patients after PICC Catheterization. Journal of Nursing, 34, 67-68 + 77 .

[25] Lin, L.Z., Zhu, X.Y., Wu, Y., et al. (2018) Application Effects of Microwave Physiotherapy in PICC Puncture Catheterization in Patients with Neoplasms. Hebei Journal of Medicine, 40, 1117-1120.

[26] Wang, J.M. (2013) Clinical Observation on Prevention of PICC Venous Thrombosis in Cancer Patients with Static and Static Pulse System. Journal of Nursing, 20, 64-65.

[27] Zhu, B.Z., Liang, S.F., Rong, J.C., et al. (2019) Study on Compression with Sphygmomanometer to Prevent Catheter-Related Venous Thrombosis after PICC. Contemporary Nurses, 26, 36-38.

[28] Jin, L., Xu, Y.Z., Wang, X.C., et al. (2015) Observation on Effect of Air Wave Pressure Theraputic Apparatus for Prevention of PICC-Related Thrombosis. Nursing Research, 29, 952-953.

[29] Li, X. (2016) The Current Status of Peripherally Inserted Central Catheter Application among 147 Tertiary Grade A Hospitals in China. Chinese Nursing Management, 16, 729-732.

[30] Zhu, S.S., Zhou, X.D., Chai, Y.P., et al. (2017) Application and Nursing of Kangxintm PICC Catheter in Patients with Neurosurgical Aneurysms. General Nursing, $15,2121-2122$.

[31] Wu, Y.R., Wang, L., Gao, S.Y., et al. (2008) Application of Domestic PICC in Intravenous Infusion of Severe Patients in Neurology Department. Medical Theory and Practice, No. 7, 837-838.

[32] Seckold, Tammy, Walker, et al. (2015) A Comparison of Silicone and Polyurethane. Journal of Vascular Access, 16, 167-177. https://doi.org/10.5301/jva.5000330

[33] Wang, C.F., Mu, D., Zhang, Y.Y., et al. (2018) Effect of Exercise Diary on Arm Exercise Compliance of PICC Patients. Modern Clinical Nursing, 17, 48-52.

[34] Zhou, X.M., Zhang, G.N., Ying, Y.P., et al. (2019) Effects of Teach Back on Fist Movement Adherence, Upper Extremity Venous Blood Flow Velocity and Catheter Related Complications in Hematologictumor Patients with PICC. Journal of Snake, 31, 127-130. 